\title{
NON-CONTACT INDUCTION HEATING AND SAAP-148 ELIMINATE PERSISTERS WITHIN MRSA BIOFILMS MIMICKING A METAL IMPLANT INFECTION
}

\author{
M. Verheul ${ }^{1}$, J.W. Drijfhout ${ }^{2}$, B.G. Pijls ${ }^{3, \S}$ and P.H. Nibbering ${ }^{1, \S, *}$ \\ ${ }^{1}$ Department of Infectious Diseases, Leiden University Medical Centre, 2300 RC Leiden, the Netherlands \\ ${ }^{2}$ Department of Immunology, Leiden University Medical Centre, 2300 RC Leiden, the Netherlands \\ ${ }^{3}$ Department of Orthopaedics, Leiden University Medical Centre, 2300 RC Leiden, the Netherlands \\ $\S$ These authors contributed equally to this work
}

\begin{abstract}
Implant-associated infections are the primary cause of complications following orthopaedic surgery. Due to biofilm and persister formation, current treatments, i.e. surgical debridement followed by antibiotics, often fail. There is an urgent need for alternative strategies to combat such infections. Therefore, the present study investigated the effects of non-contact induction heating $(\mathrm{NCIH})$, the antimicrobial peptide SAAP-148 and combinations thereof on bacterial counts in $7 \mathrm{~d}$ mature biofilms and in persister-enriched biofilms of methicillin-resistant Staphylococcus aureus (MRSA) on titanium-aluminium-niobium (TAN) discs. Enrichment of persisters was achieved by daily exposure of mature biofilms to high doses of rifampicin and ciprofloxacin for 3 consecutive days. To heat up the TAN discs, a miniaturised induction heater was built and successfully validated. Using this apparatus, $\mathrm{NCIH}$ resulting in surface temperatures up to $85^{\circ} \mathrm{C}$ eradicated all the bacteria in immature biofilms but not in mature biofilms, whereas persisters were already eliminated at surface temperatures $\geq 70{ }^{\circ} \mathrm{C}$. SAAP-148 at concentrations $>25.6 \mu \mathrm{mol} / \mathrm{L}$ reduced the persister counts in antibiotics-exposed, mature biofilms. As surface temperatures $>60^{\circ} \mathrm{C}$ can have detrimental effects on the surrounding tissues, the maximum temperature of NCIH used in combination with SAAP-148 on persisters was set to $60^{\circ} \mathrm{C}$. Results revealed that this combination was slightly more effective than the peptide or NCIH alone in eliminating biofilm-embedded persisters. NCIH and SAAP-148 can be applied both invasively and non-invasively in various treatment scenarios. Together, combinations of NCIH and SAAP-148 might be a promising treatment strategy to combat metal-implant-associated infections.
\end{abstract}

Keywords: Implant-associated infection, methicillin-resistant Staphylococcus aureus, biofilm, persisters, titanium-aluminium-niobium discs, non-contact induction heating, antimicrobial peptide, SAAP-148, prosthetic joint infection.

*Address for correspondence: Dr Peter Nibbering, Leiden University Medical Centre, Department of Infectious Diseases C5-P, 2300 RC Leiden, the Netherlands.

Telephone number: +31 715262204 Email: p.h.nibbering@lumc.nl

Copyright policy: This article is distributed in accordance with Creative Commons Attribution Licence (http://creativecommons.org/licenses/by-sa/4.0/).

\begin{tabular}{|c|c|c|c|}
\hline & List of Abbreviations & $\begin{array}{l}\text { PBS } \\
\text { PEMF }\end{array}$ & $\begin{array}{l}\text { phosphate-buffered saline } \\
\text { pulsed electro-magnetic field }\end{array}$ \\
\hline $\mathrm{AMF}$ & alternating magnetic fields & SAAP & synthetic anti-microbial and anti- \\
\hline BHI & brain heart infusion & & biofilm peptide \\
\hline BM2 & biofilm medium 2 & TAN & titanium-aluminium-niobium \\
\hline CFU & colony-forming unit & TSB & tryptone soy broth \\
\hline DAIR & $\begin{array}{l}\text { debridement-antibiotic therapy and } \\
\text { implant retention }\end{array}$ & & \\
\hline DMSO & dimethyl sulphoxide & & Introduction \\
\hline $\mathrm{MBC}$ & minimal bactericidal concentration & & \\
\hline MRSA & $\begin{array}{l}\text { methicillin-resistant Staphylococcus } \\
\text { aureus }\end{array}$ & $\begin{array}{l}\text { Anim } \\
\text { of ortl }\end{array}$ & $\begin{array}{l}\text { ciated infection is a major complication } \\
\text { urgery and is responsible for implant }\end{array}$ \\
\hline $\mathrm{NCIH}$ & non-contact induction heating & failur & treatments often fail to combat these \\
\hline
\end{tabular}


persistent infections, which results in high morbidity and mortality rates, and a major economic burden (Kapadia et al., 2014; Springer et al., 2017). Infections of (prosthetic) implants are predominantly caused by Staphylococci, such as MRSA, that form a biofilm on the implant surface (Benito et al., 2016; Pulido et al., 2008). The extracellular polymeric matrix of the biofilm protects the biofilm-embedded bacteria from the actions of antibiotics, effector cells and molecules of the immune system (Achermann et al., 2014). Also, the various bacterial subpopulations within the biofilm show different metabolic activities, which alter their response to antibiotics, i.e. subpopulations with low metabolic activity tolerate antibiotics and will therefore persist within the biofilm (Bjarnsholt et al., 2011). Upon discontinuation of the antibiotic treatment, these persisting bacteria can cause infection relapse (Harms et al., 2016), thus explaining the failure of the antibiotic treatment (Spoering et al., 2001). Other treatments that are used to remove implant-associated infections include DAIR and revision surgery (McConoughey et al., 2014; Vaz et al., 2020). Unfortunately, these treatments are invasive, often not successful and associated with additional complications.

Novel non-invasive strategies, such as heating up metal implants by using high-frequency AMF (also known as induction heating), have been proposed to reduce or even eradicate $24 \mathrm{~h}$ bacterial biofilms (Chopra et al., 2017; Pijls et al., 2017). The principle of AMF to generate heat in metal objects has been used on several biomedical technologies as it specifically heats up metals and does not directly harm the surrounding tissue (Christiansen et al., 2017). Recently, the effect of heat generation by AMF has been tested in an in vitro model of Pseudomonas aeruginosa and MRSA biofilms on metal implant mimics (Chopra et al., 2017). Exposure for longer than $3 \mathrm{~min}$ to $\sim 80^{\circ} \mathrm{C}$ results in elimination of bacteria within biofilms and increased sensitivity of bacteria to antibiotics. Similarly, heating up titanium alloys by $\mathrm{NCIH}$ results in a temperature of $80{ }^{\circ} \mathrm{C}$ after $3.5 \mathrm{~min}$ and almost total eradication of the bacterial load of MRSA $24 \mathrm{~h}$ biofilms (Pijls et al., 2020). Moreover, a synergistic effect could be observed upon combination of $60{ }^{\circ} \mathrm{C} \mathrm{NCIH}$ and antibiotics, resulting in a significant elimination of viable bacteria within biofilms (Pijls et al., 2020). Another alternative strategy for implant-associated infections is the use of antimicrobial peptides such as SAAP (Riool et al., 2017). SAAPs were developed based on the blueprint of the human antimicrobial peptide LL-37 and exert a lower rate of resistance development due to their multifunctional mechanisms of action (Fjell et al., 2011; Scott et al., 2002). Notably, SAAP-148 has shown promising anti-biofilm activity by totally eradicating MRSA biofilms from polystyrene surfaces, wounded ex vivo human skin and superficially wounded murine skin (de Breij et al., 2018). Moreover, SAAP148 is more effective than several other antimicrobial peptides in eliminating bacteria, including persisters, in mature MRSA biofilms on various surfaces, including TAN discs (Scheper et al., 2021). The aim of the present study was to assess the effect of $\mathrm{NCIH}$ and $\mathrm{NCIH}$ in combination with SAAP-148 on bacteria in biofilms on metal surfaces mimicking a metal implant-associated infection. For this purpose, persisters in $7 \mathrm{~d}$ mature biofilms were obtained by high-dose antibiotic treatment and subsequently exposed to NCIH, SAAP-148 and combinations thereof. As the TAN discs were designed to fit in the wells of a 96-well plate, a custom-built NCIH device was developed to heat up the TAN discs. The combination of NCIH and SAAP-148 was expected to combat the biofilm-embedded persisters with a high efficacy by attacking the biofilm from both the basal (implant) and top (peri-implant) side.

\section{Materials and Methods}

\section{Antibiotics and SAAP-148 peptide}

Ciprofloxacin (Sigma-Aldrich, 86393-32-0) was diluted in MilliQ water $(5.12 \mathrm{mg} / \mathrm{mL})$ and rifampicin (Sigma-Aldrich, 13292-46-1) in DMSO (4 mg/mL) and stored at $-20{ }^{\circ} \mathrm{C}$ until use. SAAP-148 peptide (sequence LKRVWKRVFKLLKRYWRQLKKPVR) was synthesised by solid phase chemistry using an automated multiple peptide synthesiser (SyroII, MultiSyntech, Witten, Germany) as described elsewhere (de Breij et al., 2018). The molecular mass of the N-terminal acetylated and C-terminal amidated peptide was confirmed by mass spectrometry and the purity of the peptide exceeded $95 \%$, as determined by reverse phase high-performance liquid chromatography and detection at $214 \mathrm{~nm}$. The lyophilised peptides were stored at $-20^{\circ} \mathrm{C}$ until use.

\section{TAN discs}

Medical grade titanium-7 \% aluminium-6 \% niobium (TAN; iso5832/11) discs (diameter $5 \mathrm{~mm}$, height $1.5 \mathrm{~mm}$ ) with a handle allowing gentle removal of the discs from the wells made specifically to fit in 96-well plates were a kind gift of Dr TF Moriarty (AO Research Institute, Davos, Switzerland). For re-use, TAN discs were rinsed and submerged overnight in $70 \% \mathrm{EtOH}$, after which they were air-dried and autoclaved.

\section{NCIH}

TAN discs were exposed to a PEMF of $101 \mathrm{kHz}$ at a maximum of $135 \mathrm{~W}$ from a custom-built induction heater (Fig. 1a). The induction heater featured a solenoid type coil with 10 turns of $6 \mathrm{~mm}$ copper tubing and it was designed to accommodate a $50 \mathrm{~mL}$ plastic centrifuge tube. This tube was equipped with a silicon mould in the centre to fit a $2 \mathrm{~mL}$ micro-tube with the TAN disc inside. This set-up was designed to consistently place the TAN disc in the centre of the PEMF generated by the solenoid coil, therefore allowing temperature control by adjusting the heating time when the association between time and 
temperature was known. The relationship between time and temperature was determined in triplicate using two fibre-optic temperature sensors connected to a fibre-optic signal conditioner (Neoptix, ReFlex-4; Neoptix Inc, Quebec City Canada; Fig. 1b). Fibre-optic temperature sensors were not affected nor heated by the PEMF, therefore ensuring reliable temperature measurements in the presence of a PEMF.

\section{Culture of MRSA}

Frozen stocks of MRSA LUH14616 (sequence type 247 , NCCB 100829 , kindly provided by Dr $S$ Croe, Department of Medical Microbiology, Maastricht University Medical Centre, Maastricht, the Netherlands) in $20 \%$ glycerol (Thermo Fisher Diagnostic BV, 1200.36.001) were thawed to spread on Trypcase Soy Agar + $5 \%$ sheep blood plates (Biomerieux, Marcy-1'Étoile, France, 43009) and cultured overnight at $37^{\circ} \mathrm{C}$. Subsequently, several colonies were taken from these plates and cultured in TSB medium (Oxoid, Basingstoke, Hampshire, $\mathrm{UK}, \mathrm{CM} 0129)$ for $2.5 \mathrm{~h}$ at $200 \mathrm{rpm}$ and $37^{\circ} \mathrm{C}$. The mid-logarithmic phase bacteria were harvested by centrifugation $(1,000 \times g$ for $10 \mathrm{~min})$, washed with PBS ( $\mathrm{pH} 7.4)$ and then, based on the optical density at $600 \mathrm{~nm}$, diluted to $1 \times 10^{7} \mathrm{CFU} / \mathrm{mL}$ in the desired medium.

\section{MRSA biofilm and persister formation}

MRSA was diluted in BHI broth (Oxoid, CM1135) for $7 \mathrm{~d}$ biofilms and in BM2 medium [62 $\mathrm{mmol} / \mathrm{L}$ potassium phosphate buffer $(\mathrm{pH} 7)$ with $7 \mathrm{mmol} / \mathrm{L}$ $\left(\mathrm{NH}_{4}\right) 2 \mathrm{SO}_{4^{\prime}}, 200 \mathrm{mmol} / \mathrm{L} \mathrm{MgSO}_{4^{\prime}} 10 \mathrm{mmol} / \mathrm{L} \mathrm{FeSO}_{4^{\prime}}$ $40 \%$ glucose $+50 \%$ casamino acids)] for $24 \mathrm{~h}$ biofilms Briefly, $100 \mu \mathrm{L}$ of bacterial suspension was pipetted into 96-well plates containing TAN discs. After $24 \mathrm{~h}$ or $7 \mathrm{~d}$, the wells were washed and the discs with biofilms were gently transferred to polystyrene 96-well plates or polypropylene 96-well plates for exposure to antibiotics or SAAP-148, respectively. Plates with $24 \mathrm{~h}$ biofilms were sealed with non-breathable plastic film sealers (AmpliStar Adhesive Plate Sealers, Westburg, Leusden, the Netherlands, WB 2-3830). Mature biofilms on plates were sealed with breathable rayon film sealers (VWR, 391-1262). For enrichment in persisters, mature biofilms were washed daily with PBS and then $100 \mu \mathrm{L}$ of BHI suspension with $10 \times$ the MBC of ciprofloxacin $(1,280 \mu \mathrm{g} / \mathrm{mL})$ and rifampicin $(10 \mu \mathrm{g} / \mathrm{mL})$ were added. After $24 \mathrm{~h}$, the antibiotics were refreshed daily for up to $5 \mathrm{~d}$. Controls received similar concentrations of BHI suspension in MilliQ water. Biofilms were allowed to form in a plastic box at $37^{\circ} \mathrm{C}$, to maintain a humidified environment. Medium controls were used to monitor any possible contamination.

Effect of treatments on bacterial counts in biofilms Biofilms were exposed to $\mathrm{NCIH}$ at various target temperatures $\left(60\right.$ to $\left.85^{\circ} \mathrm{C}\right)$, to SAAP-148 peptide or to combinations of NCIH and SAAP-148 at various dilutions in PBS for $2 \mathrm{~h}$. For these combinations, biofilms were first exposed to the peptide and subsequently to NCIH. Prior to treatment, planktonic bacteria were removed from the wells by 2 washes with PBS. After treatment, TAN discs with biofilms were transferred to 96-well plates containing $100 \mu \mathrm{L}$ of PBS and sonicated $(10 \mathrm{~min}$ at $40 \mathrm{kHz})$. Serial dilutions of bacterial suspensions were plated on Mueller Hinton agar plates (Oxoid, CM0337) and $\mathrm{CFU}$ was counted after incubation overnight $\left(37^{\circ} \mathrm{C}\right)$.

\section{Data analysis}

Kruskal-Wallis tests followed by Mann-Whitney U tests (GraphPad Software 9) were performed to determine the significance of the difference in CFUs between treated and control samples. $p<0.05$ was considered statistically significant.

\section{Results}

Calibration of the induction heating equipment The temperature at the surface of TAN discs was measured every $1 \mathrm{~s}$ during a period of $8 \mathrm{~min}$ of

a
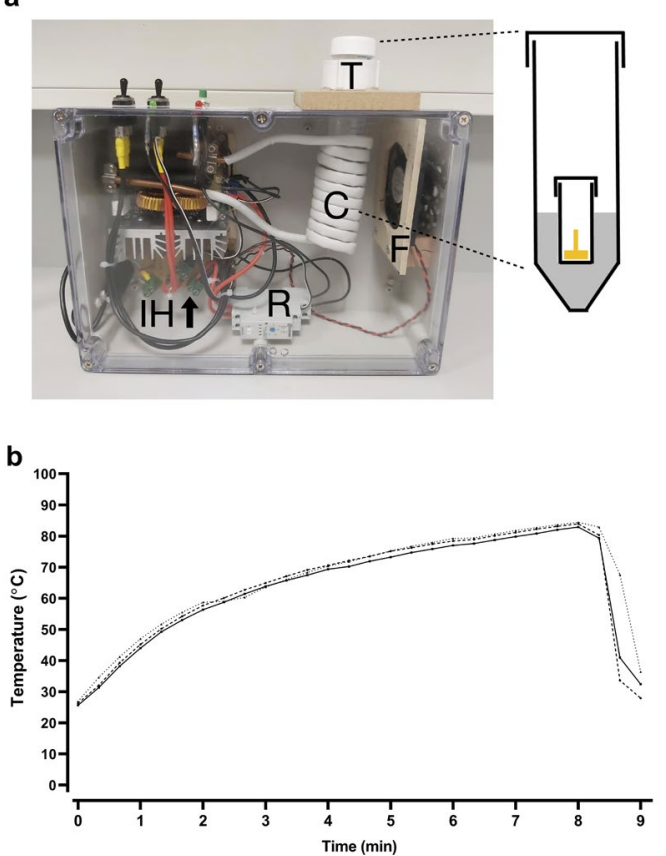

Fig. 1. The relationship between duration of induction heating by the custom-built NCIH equipment and the surface temperature of TAN discs. (a) The custom-built induction heater and a schematic drawing of the orange TAN disc in the $2 \mathrm{~mL}$ micro-tube, placed in a silicon mould (gray) in the centre of the $50 \mathrm{~mL}$ plastic centrifuge tube (IH = induction heater circuit; $\mathrm{C}=$ coil to generate a pulsed electromagnetic field; $\mathrm{T}=$ docking station for $50 \mathrm{~mL}$ tube; $\mathrm{F}$ = fan for convection cooling of coil and induction heater circuit; $\mathrm{R}=$ time release to control heating time). (b) Fibre-optic measurements were performed to determine the relationship between the duration of NCIH and the surface temperature of the TAN disc in PBS. Results are means of duplicates from 3 independent runs plotted every $20 \mathrm{~s}$ for $9 \mathrm{~min}$. 
NCIH using fibre-optic sensors to establish the relationship between the duration of $\mathrm{NCIH}$ and the surface temperature of TAN discs in PBS (Fig. 1b). Results revealed that within the first $2 \mathrm{~min}$ the surface temperature rapidly increased from $27^{\circ} \mathrm{C}$ to $60^{\circ} \mathrm{C}$. Thereafter, the surface temperature linearly increased by $10^{\circ} \mathrm{C}$ every 2 min until $80^{\circ} \mathrm{C}$ and, subsequently, increased up to $85^{\circ} \mathrm{C}$ during the $2 \mathrm{~min}$ interval. After transfer of the TAN discs to wells containing PBS at $37^{\circ} \mathrm{C}$, the temperature of the discs dropped to ambient temperature within $1 \mathrm{~min}$. Based on these data, a time relay was used to control the heating time. The time for induction heating of TAN discs in the presence of $100 \mu \mathrm{L}$ of PBS were set at $2 \mathrm{~min}$ for $60{ }^{\circ} \mathrm{C}, 4 \mathrm{~min}$ for $70{ }^{\circ} \mathrm{C}, 6 \mathrm{~min}$ for $80^{\circ} \mathrm{C}$ and $8 \mathrm{~min}$ for $85^{\circ} \mathrm{C}$.

Effect of heat-treatment duration on the bacterial counts in $7 \mathrm{~d}$ mature biofilms

To determine if reaching the temperature rather than the duration of the exposure to that temperature killed the bacteria within the biofilms, the number of viable bacteria within $7 \mathrm{~d}$ mature biofilms on TAN discs was determined upon exposure to a range of temperatures $\left(60,70\right.$ or $\left.80{ }^{\circ} \mathrm{C}\right)$ using a heat-block for various durations. Results revealed a heatdependent reduction in biofilm-embedded bacteria, with a maximal reduction down to $500 \mathrm{CFU} / \mathrm{mL}$ after exposure to $80^{\circ} \mathrm{C}$. Longer exposure of biofilms (4 min compared to $2 \mathrm{~min}$ ) to the heat-block at $60^{\circ} \mathrm{C}$ did not show a further reduction in bacterial load. Further, subjecting the biofilms for $4 \mathrm{~min}$ at 70 and $80^{\circ} \mathrm{C}$ exerted a maximal, negligible 10 -fold reduction in CFU/mL compared to 2 min exposure to these temperatures. Data indicated that longer durations at a selected temperature resulted in a steady-state

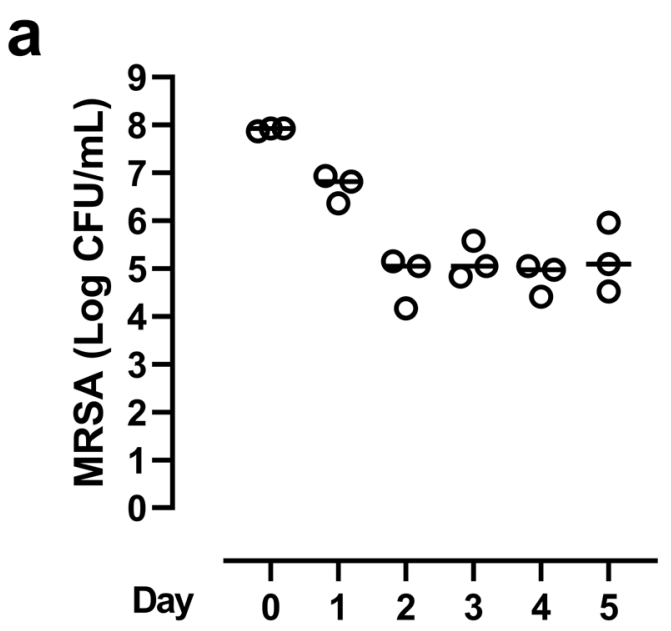

antibacterial effect rather than a further reduction in bacterial counts in the biofilms.

\section{Development of the in vitro model for persisters in biofilms}

To develop an in vitro model that partially mimicked metal implant-associated infections, the effects of daily exposure to high doses $(10 \times \mathrm{MBC})$ of rifampicin and ciprofloxacin on bacteria residing within $7 \mathrm{~d}$ mature MRSA biofilms on TAN discs for a period of $5 \mathrm{~d}$ were determined. Results revealed that the number of viable bacteria in the biofilms rapidly dropped $(p<0.05)$ from approximately $1 \times 10^{8} \mathrm{CFU} /$ $\mathrm{mL}$ to about $1 \times 10^{5} \mathrm{CFU} / \mathrm{mL}$ during the first $2 \mathrm{~d}$ of antibiotic exposure and thereafter the bacteria tolerated the antibiotics for at least an additional $3 \mathrm{~d}$ (Fig. 2a). The numbers of viable bacteria in control biofilms did not change $(p>0.05)$ during these $5 \mathrm{~d}$ (Fig. 2b). Based on these data, $3 \mathrm{~d}$ of antibiotic treatment has been used in further experiments to study the effects of innovative treatments on persisters in biofilms.

\section{Effect of induction heating on bacteria in biofilms and persisters}

To allow for a comparison with previously published studies on NCIH with $24 \mathrm{~h}$ biofilms, the effects of $\mathrm{NCIH}$ on bacteria in $24 \mathrm{~h}$ MRSA biofilms on TAN discs were first determined after various durations of induction heating. Results revealed a surface temperature-dependent reduction $(p<0.05)$ in bacterial counts, with complete eradication of the bacteria seen at a surface temperature of $85^{\circ} \mathrm{C}$ (Fig. 3a). However, a maximum 5-Log reduction in bacterial counts was seen for MRSA in $7 \mathrm{~d}$ mature biofilms on TAN discs after heating the surface

b

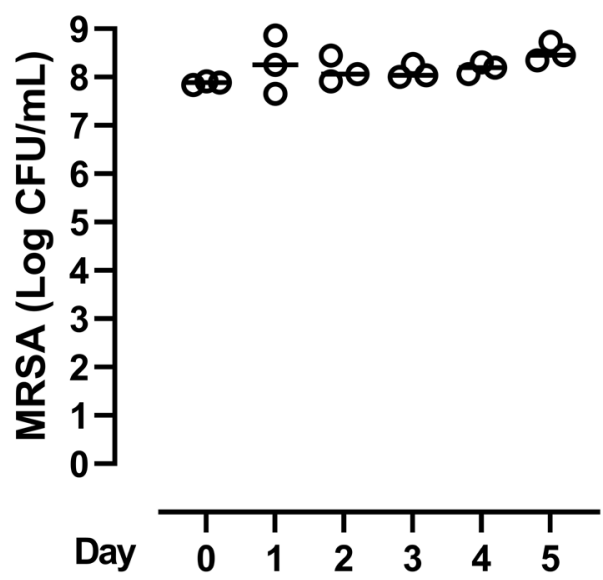

Fig. 2. Effect of high-dose antibiotics on bacteria in mature biofilms. $7 \mathrm{~d}$ mature Staphylococcus aureus LUH14616 (MRSA) biofilms on TAN discs were exposed daily for up to 5 consecutive days to a combination of (a) 10× MBC rifampicin and ciprofloxacin or (b) the diluent of the antibiotics as control. After each day, TAN discs with biofilms were transferred to wells containing PBS, sonicated and thereafter the number of viable bacteria was assessed microbiologically by counting the CFU. Results are from 3 independent experiments each performed in triplicate; the solid line indicates the median Log CFU/mL. Significance of the differences between the various surface temperatures was calculated by Kruskal-Wallis test (a: $p<0.05$, b: $p>0.05)$. 
to $\geq 70{ }^{\circ} \mathrm{C}$ (Fig. 3b), indicating that $\mathrm{NCIH}$ was not sufficient to eradicate all biofilm-encased bacteria. Regarding the persister model, NCIH of the TAN discs to $60^{\circ} \mathrm{C}$ led to a 10 -fold reduction in the number of persisters (Fig. 3c), whereas heating to surface temperatures $\geq 70{ }^{\circ} \mathrm{C}$ resulted in total eradication of persisters within the biofilms $(p<0.001)$.

Effect of SAAP-148 monotherapy and in combination with induction heating on persisters within biofilms Since persisters are the main cause of therapy failure in implant-associated infections, the effect of SAAP148 on persisters in antibiotics-exposed mature biofilms on TAN discs was first confirmed. Results revealed a dose-dependent reduction $(p<0.05)$ in bacterial counts for persisters in a biofilm by peptide concentrations $>12.8 \mu \mathrm{mol} / \mathrm{L}$, with almost all persisters eradicated at the highest peptide concentration (51.2 $\mu \mathrm{mol} / \mathrm{L})$ (Fig. 4). Next, the effect of SAAP-148 followed by induction heating to a surface temperature of $60{ }^{\circ} \mathrm{C}$ on persisters in biofilms was determined. Results showed that this combination was slightly more effective in reducing persisters in antibiotics-exposed, mature biofilms than the peptide or NCIH alone. Mann-Whitney U test indicated that the combination of NCIH with $12.8 \mu \mathrm{mol} / \mathrm{LSAAP}-148$ was significantly $(p<0.05)$ more effective than the peptide or induction heating alone (Fig 4).

\section{Discussion}

Two innovative, non-antibiotic strategies to combat metal implant-associated infections with MRSA were investigated using a novel in vitro model (Scheper et al., 2021). For this model, $7 \mathrm{~d}$ mature biofilms on TAN discs were developed and exposed for $3 \mathrm{~d}$ to high doses of rifampicin and ciprofloxacin, an antibiotic combination that is commonly used to treat implantassociated infections caused by Staphylococcus aureus/ MRSA. Control experiments indicated that the surviving bacteria indeed developed tolerance to the subsequent antibiotic treatment. First, the effects of $\mathrm{NCIH}$ and of the novel antimicrobial peptide SAAP148 on bacterial subpopulations including persisters in biofilms were determined. To circumvent undesirable side-effects of these treatments on peri- a

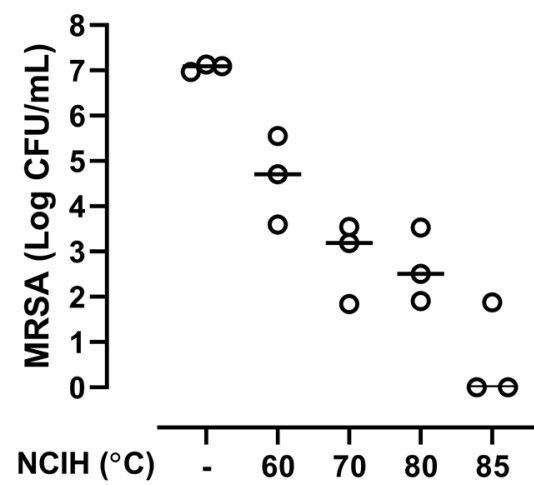

b

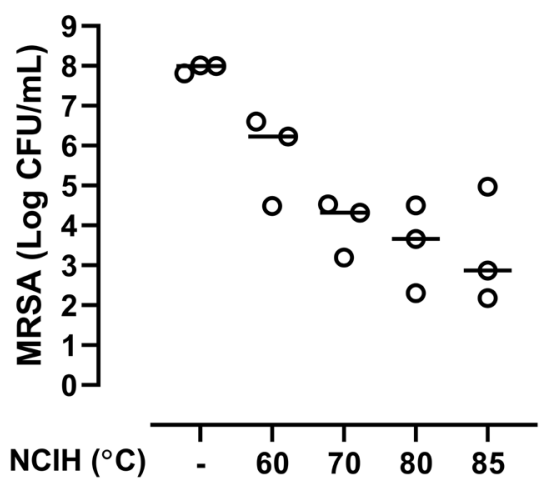

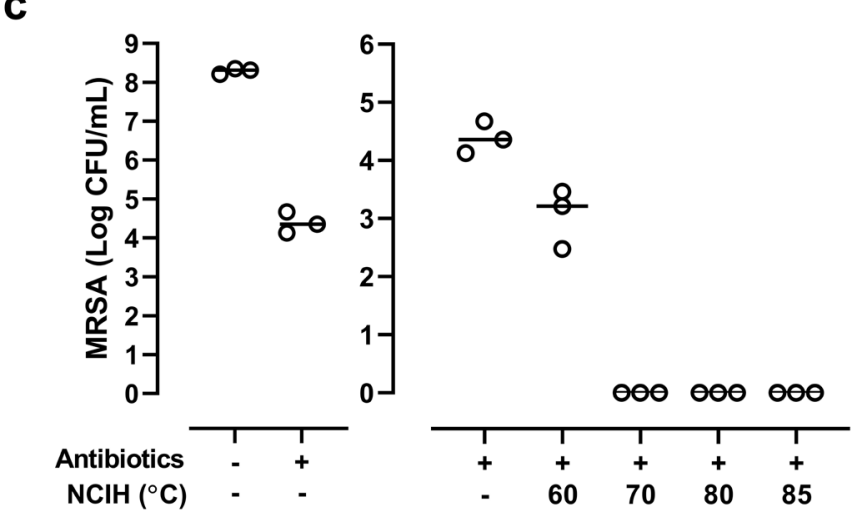

Fig. 3. Effect of surface temperature on bacteria, including persisters, residing in biofilms. (a) $24 \mathrm{~h}$ Staphylococcus aureus LUH14616 (MRSA) biofilms, (b) $7 \mathrm{~d}$ mature MRSA biofilms and (c) $7 \mathrm{~d}$ mature, $3 \mathrm{~d}$ antibiotics (10× MBC of rifampicin and ciprofloxacin)-exposed MRSA biofilms on TAN discs were transferred to vials containing PBS for surface heating by NCIH for various intervals. Thereafter, the TAN discs with biofilms were transferred to wells containing PBS and subjected to sonication for microbiological determination of the number of viable bacteria. Results are from 3 independent experiments each performed in quadruplicate; the solid line indicates the median Log CFU/mL. Significance of the differences between the various surface temperatures was calculated by Kruskal-Wallis test (a,c: $p<0.0001, \mathbf{b}: p<0.05)$. 
implant tissues, the second strategy focused on establishing the possible additive effects of combining $\mathrm{NCIH}$ with SAAP-148 on the counts of persisters in biofilms.

Results showed a temperature-dependent reduction in bacterial counts in immature biofilms with complete bacterial eradication seen at a surface temperature of $85{ }^{\circ} \mathrm{C}$, whereas bacterial counts in mature biofilms decreased in a temperaturedependent fashion up to $70{ }^{\circ} \mathrm{C}$ and thereafter remained unchanged. The observed effect of $\mathrm{NCIH}$ on immature biofilms is in line with an earlier observation that almost all bacteria within $24 \mathrm{~h}$ biofilms are eliminated by a heat shock of $85^{\circ} \mathrm{C}$ (Pijls et al., 2020). The difference in susceptibility of bacteria in mature and immature biofilms to induction heating could be related to the amount of protective extracellular matrix, which is considerably larger in mature biofilms. Further, the present study focused predominantly on (persister-enriched) mature biofilms since others have shown that $24 \mathrm{~h}$ biofilms may not be optimal to study the effects of novel strategies and drugs on bacteria in mature biofilms (Dice et al., 2009). In agreement, Cazander et al. (2010) reported that at least 6-8 $\mathrm{d}$ are required to develop the mature biofilm profile that is observed in clinical implant-associated infections. Since the persister subpopulation is the main cause of treatment failure in metal implant-associated infections, the findings that $\mathrm{NCIH}$ resulting in temperatures $\geq 70{ }^{\circ} \mathrm{C}$ completely eradicated all bacteria in persister-enriched mature biofilms are of particular importance. The difference in the efficacy of NCIH on bacteria in mature biofilms and persisters within biofilms may be related to the bacterial numbers in these models; the number of persisters being 10,000-fold lower than the number of bacteria in mature biofilms. As reported earlier (Scheper et al., 2021), SAAP-148 peptide at the highest non-haemolytic concentration (de Breij et al., 2018) effectively reduces persister counts in antibioticsexposed, mature biofilms, but does not eradicate all persisters.

Both NCIH and SAAP-148 should not result in adverse effects, such as cytotoxicity. In this context, temperatures $>60{ }^{\circ} \mathrm{C}$ were considered undesirable due to the risk of transmission, to some extent, of heat to the peri-implant tissue. This is based on the observation that induction heating of a titanium memory rod up to $60{ }^{\circ} \mathrm{C}$ in rats does not cause necrosis (Müller et al., 2014). Chopra et al. (2017) reported that in vivo AMF exposure reaching temperatures up to $100{ }^{\circ} \mathrm{C}$ results in (irreversible) damage to tissues closely surrounding the metal implant. The present study revealed that exposure of antibiotics-exposed, mature biofilms to SAAP148 for $2 \mathrm{~h}$ followed by induction heating to $60{ }^{\circ} \mathrm{C}$ was slightly more effective than the heat shock or the peptide alone, with the highest concentration of the peptide in combination with induction heating completely eradicating all persisters in biofilms. Of note, the effect of the combination did not depend on the order in which the peptide and induction heating were applied (results not shown). A possible explanation for this enhanced effect of NCIH in combination with SAAP-148 on persisters in mature biofilms could be that the treatments attacked the bacteria in the biofilms from different sides, i.e. $\mathrm{NCIH}$ from the basal side (implant) and the peptide from the top (peri-implant). In addition, the modes of action of these treatments also differ completely. Based on these findings, it was concluded that combinations of NCIH and SAAP-148 could become a promising

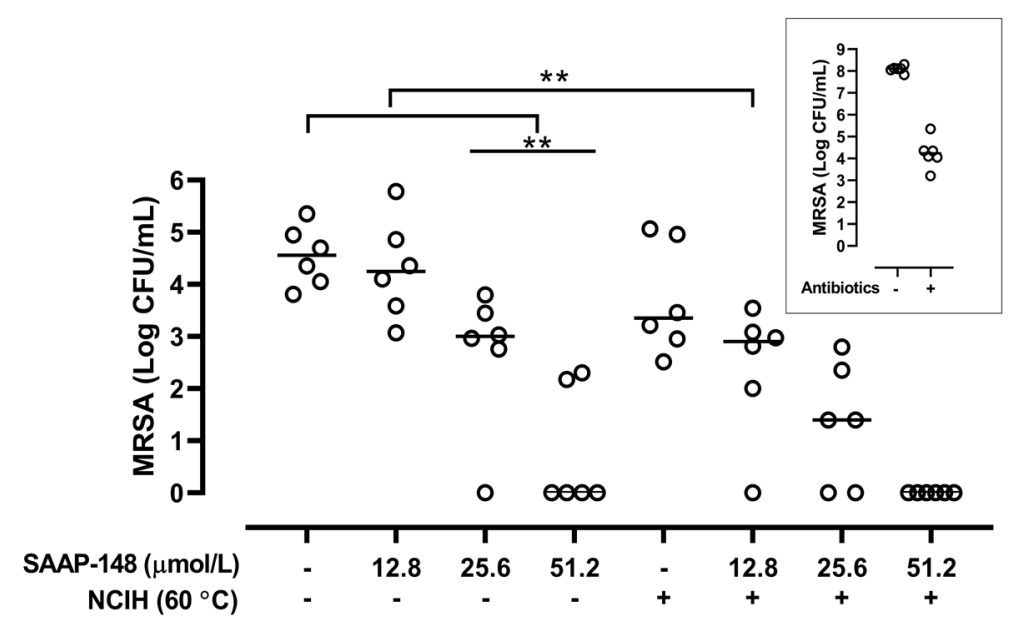

Fig. 4. Effect of SAAP-148 in combination with NCIH on persisters within MRSA biofilms. $7 \mathrm{~d}$ mature Staphylococcus aureus LUH14616 (MRSA) biofilms on TAN discs were exposed daily to high-dose antibiotics (10 $\times$ MBC of rifampicin and ciprofloxacin) and subjected for $2 \mathrm{~h}$ to increasing concentrations of SAAP-148 with or without subsequent $\mathrm{NCIH}$ to $60^{\circ} \mathrm{C}$. Insert indicates the effect of antibiotics on bacteria in the mature biofilm. All biofilms were subjected to sonication for microbiological determination of the number of viable bacteria. Results are from 6 independent experiments each performed in quadruplicate with a solid line indicating the median $\log \mathrm{CFU} / \mathrm{mL}$. Significance of the differences between the various conditions was calculated by Kruskal-Wallis $(p<0.0001)$ and subsequently Mann-Whitney $\mathrm{U}$ tests. ${ }^{* *} p<0.01$. 
strategy for the treatment of metal implant-associated infections.

To heat up the TAN discs in a controlled fashion, a miniaturised version of the NCIH apparatus was built and successfully validated. This equipment was designed to reach a target temperature rather than to maintain the temperature for a prolonged period, as was the case in previous NCIH studies (Pijls et al., 2020). The rationale for this approach was twofold. First, a closed feedback temperature control system for non-invasive heating at $60{ }^{\circ} \mathrm{C}$ may be difficult to achieve clinically (Cheng et al., 2018), indicating that the NCIH model featured here represents a practical approach. Secondly, temperature rather than duration of that temperature may be more effective against bacteria. In agreement, experiments investigating the effects of duration of exposure to a temperature using a heat block revealed that longer durations at a selected temperature resulted in a steady-state antibacterial effect rather than a further reduction in bacterial counts in biofilms. In line with this, recent studies on thermal stability of proteins among different species (e.g. human, bacterial and fungi) have suggested that stability of key proteins of these pathogens is affected by lower temperatures than that of human proteins (Leuenberger et al., 2017; O'Toole et al., 2015). The future medical application of NCIH could be divided into non-invasive and invasive use. During the non-invasive use, the metal implant is heated non-invasively through the skin, while great care is taken to avoid excessive heating to areas where the implant is fixed to the bone or areas that are in close contact with crucial anatomical structures such as nerves and major blood vessels. This may be performed in a segmental way with tailored heating protocols for each segment: segmental induction heating (Pijls et al., 2018). In the future, the non-invasive application of induction may first help patients for whom surgical treatment is not possible and who, for instance, receive suppression antibiotic therapy. NCIH will most likely be part of a multi-modality treatment that also involves antibiotics and adjuvants (non-antibiotic chemical agents). Alternatively, NCIH can be used invasively, e.g. during surgery, to increase the effectiveness of the surgical procedure such as in DAIR: NCIH kills micro-organisms by heat and it could be used to heat the implant and parts of the implant that cannot be reached and mechanically cleaned. The soft tissue can be kept away from the heated part of the implant to protect it from thermal damage. Furthermore, surgery allows for direct temperature control by direct temperature measurement (e.g. thermocouple) or infrared thermal imaging. However, it should be mentioned that the current in vitro model for metal implant-associated infections suffers from some limitations. First, all experiments were performed with only a single strain (although a clinical isolate) of MRSA (de Breij et al., 2018). Another major limitation is the absence of peri-implant tissue and local factors, such as exudate or wound fluid. These limitations may be circumvented in future experiments by using TAN discs in 12-well plates containing cultures of relevant cell types, such as myeloid-derived suppressive cells (Bosch et al., 2020), inflammatory macrophages and wound fluid collected from patients undergoing prosthetic joint or hip replacement surgery. While the current experiments have focused on the effects of the combination treatment on persisters in mature biofilms, the effects of this combination on bacteria in mature biofilms remain unexplored. Lastly, it is unknown whether bacteria in mature biofilms can become tolerant to induction heating in the unlikely event of receiving multiple heat shocks as a treatment.

\section{Conclusion}

Neither NCIH nor SAAP-148 peptide at clinically desirable conditions could eradicate all MRSA subpopulations residing within antibiotics-exposed, mature biofilms on TAN discs. Combinations of SAAP-148 and induction heating to $60{ }^{\circ} \mathrm{C}$ were slightly more effective than these approaches alone. Of note, the combination of the highest nonhaemolytic concentration of SAAP-148 and induction heating to $60{ }^{\circ} \mathrm{C}$ resulted in complete eradication of all bacterial subpopulations in MRSA biofilms. Furthermore, NCIH and the peptide can be applied both invasively and non-invasively. Therefore, combinations of NCIH and SAAP-148 may be useful as a treatment for patients with implant-associated infections in whom the current treatment has failed. Moreover, such combinations could also be applied at an earlier stage of the treatment, e.g. during debridement of the implant, or even when replacing the current treatment involving debridement and antibiotics.

\section{Acknowledgements}

We thank Dr MGJ de Boer and Dr H Schepers (Department of Infectious Diseases, Leiden University Medical Centre) for their helpful and encouraging discussions.

One of the authors (BGP) is funded by ZonMW under a VENI-grant [09150161810084].

One of the authors (BGP) is listed as a co-inventor on a provisional patent application from the Leiden University Medical Centre (WO2020/067898). The Leiden University Medical Centre is also holder of patent number WO2015088344 (co-inventors JWD and $\mathrm{PHN}$ ) relating to the peptide described in the present study.

\section{References}

Achermann Y, Goldstein EJ, Coenye T, Shirtliff ME (2014) Propionibacterium acnes: from commensal to 
opportunistic biofilm-associated implant pathogen. Clin Microbiol Rev 27: 419-440.

Benito N, Franco M, Ribera A, Soriano A, Rodriguez-Pardo D, Sorlí L, Fresco G, FernándezSampedro M, Dolores Del Toro M, Guío L, SánchezRivas E, Bahamonde A, Riera M, Esteban J, BaraiaEtxaburu JM, Martínez-Alvarez J, Jover-Sáenz A, Dueñas C, Ramos A, Sobrino B, Euba G, Morata L, Pigrau C, Coll P, Mur I, Ariza J, REIPI (Spanish network for research in infectious disease) group for the study for prosthetic joint infections (2016) Time trends in the aetiology of prosthetic joint infections: a multicentre cohort study. Clin Microbiol Infect 22: 732.e1-8.

Bjarnsholt T, Moser C, Jensen PO, Hoiby N (2011) Biofilm infections. Springer. pp: 215-225.

de Breij A, Riool M, Cordfunke RA, Malanovic N, de Boer L, Koning RI, Ravensbergen E, Franken M, van der Heijde T, Boekema BK, Kwakman PHS, Kamp N, El Ghalbzouri A, Lohner K, Zaat SAJ, Drijfhout JW, Nibbering PH (2018) The antimicrobial peptide SAAP-148 combats drug resistant bacteria and biofilms. Sci Transl Med 10: eaan4044. DOI: 10.1126/ scitranslmed.aan4044.

Bosch ME, Bertrand BP, Heim CE, Alqarzaee AA, Chaudhari SS, Aldrich AL, Fey PD, Thomas VC, Kielian T (2020) Staphylococcus aureus ATP synthase promotes biofilm persistence by influencing innate immunity. mBio 11: e01581-20. DOI: 10.1128/ mBio.01581-20.

CazanderG, Van de VeerdonkMC, VandenbrouckeGrauls CMJE, Schreurs MWJ, Jukema GN (2010) Maggot excretions inhibit biofilm formation on biomaterials. Clin Orthop Relat Res 468: 2789-2796.

Cheng B, Chatzinoff Y, Szczepanski D, Bing C, Shaikh S, Wyman O, Perry CE, Richardson JA, Burns DK, Evers BM, Greenberg DE, Chopra R (2018) Remote acoustic sensing as a safety mechanism during exposure of metal implants to alternating magnetic fields. PLoS One 13: e0197380. DOI: 10.1371/ journal.pone.0197380

Chopra R, Shaikh S, Chatzinoff Y, Munaweera I, Cheng B, Daly SM, Xi Y, Bing C, Burns D, Greenberg DE (2017) Employing high-frequency alternating magnetic fields for the non-invasive treatment of prosthetic joint infections. Sci Rep 7: 7520. DOI: 10.1038/s41598-017-07321-6.

Christiansen MG, Howe CM, Bono DC, Perreault DJ, Anikeeva P (2017) Practical methods for generating alternating magnetic fields for biomedical research. Rev Sci Instrum 88: 084301. DOI: 10.1063/1.4999358.

Dice B, Stoodley P, Buchinsky F, Metha N, Ehrlich GD, Hu FZ (2009) Biofilm formation by ica-positive and ica-negative strains of Staphylococcus epidermidis in vitro. Biofouling 25: 367-375.

Fjell CD, Hiss JA, Hancock RE, Schneider G (2011) Designing antimicrobial peptides: form follows function. Nat Rev Drug Discov 11: 37-51.

Harms A, Maisonneuve E, Gerdes K (2016) Mechanisms of bacterial persistence during stress and antibiotic exposure. Science 354: aaf4268. DOI: 10.1126/science.aaf4268.

Kapadia BH, McElroy MJ, Issa K, Johnson AJ, Bozic KJ, Mont MA (2014) The economic impact of periprosthetic infections following total knee arthroplasty at a specialized tertiary-care center. J Arthoplasty 29: 929-932.

Leuenberger P, Ganscha S, Kahraman A, (2017) Cell-wide analysis of protein thermal unfolding reveals determinants of thermostability. Science 355: eaai7825. DOI: 10.1126/science.aai7825.

McConoughey SJ, Howlin R, Granger JF, Manring MM, Calhoun JH, Shirtlif M, Kathju S, Stoodley P (2014) Biofilms in periprosthetic orthopedic infections. Future Microbiol 9: 987-1007.

Müller CW, ElKashef T, Pfeifer R, Decker S, Neunaber C, Meier K, Fehr M, Wesling V, Gösling T, Hurschler C, Krettek C (2014) Transcutaneous electromagnetic induction heating of an intramedullary nickel-titanium shape memory implant. Int Orthop 38: 2551-2557.

O'Toole A, Ricker EB, Nuxoll E (2015) Thermal mitigation of Pseudmonas aeruginosa biofilms. Biofouling 31: 664-675.

Pijls BG, Sanders IMJG, Kuijper EJ, Nelissen RGHH (2017) Non-contact electromagnetic induction heating for eradicating bacteria and yeasts on biomaterials and possible relevance to orthopaedic implant infections: in vitro findings. Bone Joint Res 6: 323-330.

Pijls BG, Sanders IMJG, Kuijper EJ, Nelissen RGHH (2018) Segmental induction heating of orthopaedic metal implants. Bone Joint Res. 7: 609619.

Pijls BG, Sanders IMJG, Kuijper EJ, Nelissen RGHH (2020) Synergy between induction heating, antibiotics and N-acetylcysteine eradicates Staphylococcus aureus from biofilm. Int J Hyperthermia 37: 130-136.

Pulido L, Ghanem E, Joshi A, Purtill JJ, Parvizi J (2008) Periprosthetic joint infection: the incidence, timing, and predisposing factors. Clin Orthop Relat Res 466: 1710-1715.

Riool M, de Breij A, Drijfhout JW, Nibbering PH, Zaat SAJ (2017) Antimicrobial peptides in biomedical device manufacturing. Front Chem 5: 63. DOI: 10.3389/fchem.2017.00063.

Riool M, de Breij A, de Boer L, Kwakman PHS, Cordfunke RA, Cohen O, Malanovic N, Emanual N, Lohner K, Drijfhout JW, Nibbering PH, Zaat SAJ (2017) Controlled release of LL-37-derived synthetic antimicrobial and antibiofilm peptides SAAP-145 and SAAP-276 prevents experimental biomaterialassociated Staphylococcus aureus infection. Adv Funct Mater 27: 1-11.

Scheper H, Wubbolts JM, Verhagen JAM, de Visser AW, van der Wal RJP, Visser LG, de Boer MG, Nibbering PH (2021) SAAP-148 eradicates MRSA persisters within mature biofilm models simulating prosthetic joint infection. Front Microbiol 12: 625952. DOI: 10.3389/fmicb.2021.625952. 
Scott MG, Davidson DJ, Gold MR, Bowdish D, Hancock REW (2002) The human antimicrobial peptide LL-37 is a multifunctional modulator of innate immune responses. J Immunol 169: 3883-3891.

Spoering AL, Lewis K (2001) Biofilms and planktonic cells of Pseudomonas aeruginosa have similar resistance to killing by antimicrobials. J Bacteriol 183: 6746-6751.

Springer BD, Cahue S, Etkin CD, Lewallen DG, McGrory BJ (2017) Infection burden in total hip and knee arthroplasties: an international registry-based perspective. Arthroplast Today 3: 137-140.

Vaz K, Scarborough M, Bottomley N, Kendrick B, Taylor A, Price A, Alvand A, Jackson W (2020) Debridement, antibiotics and implant retention (DAIR) for the management of knee prosthetic joint infection. Knee 27: 2013-2015.

\section{Discussion with Reviewer}

Jean-Paul Pirnay: Do you plan to perform animal studies in the near future? If so, which model would you consider?

Authors: In vitro data indicated that SAAPs and $\mathrm{NCIH}$ are highly promising strategies to eliminate implant-associated biofilm infections. Clearly, the next step will be to study the efficacy of these strategies in animal models. SAAP-145 injected alongside infected subcutaneously inserted titanium implants is effective in reducing bacterial counts on the implants, but not in the peri-implant tissue (Riool et al., 2017). In addition, bacterial colonisation of titanium implants coated with this peptide incorporated in a polymer lipid encapsulation is considerably less than that of uncoated implants, whereas the bacterial counts in the peri-implant tissue do not differ between the coated and uncoated implants (Riool et al., 2017). Obviously, these studies suffer from several limitations, including the biofilms in these models being immature. The efficacy of noncontact induction heating has not yet been studied in vivo and/or in animal models. However, we have recently obtained a grant to study the efficacy of $\mathrm{NCIH}$ and other strategies to combat implantassociated infections in animal models. To address this aim, we will develop an animal model for metal implant-associated mature biofilm infections or adapt current animal models (Zimmerli et al., 1982, additional reference).

Jean-Paul Pirnay: Are you developing a device suitable for human therapy?

Authors: It is our intention to translate this technology from in vitro research to human therapy that can be used clinically. In the near future, we envision a device that heats the infected metal implant during a surgical debridement procedure, killing and weakening the micro-organisms in the biofilm with induction heat, so that it adds to the present standard of care. Presently, patients with infected implants will undergo long and extensive treatments consisting of multiple surgical procedures and antibiotic courses for several months (Tande and Patel, 2014, additional reference). These treatments often involve extensive revision procedures, which may not be possible in patients with high comorbidity factors. Furthermore, increasing antibiotic resistance of bacteria raises concern and limits choices of antibiotics. Therefore, it is very important that new treatments are developed to cure biofilm-infected implants (Anguita-Alonso et al., 2005; Ravi et al., 2015, additional references).

\section{Additional References}

Anguita-Alonso P, Hanssen AD, Osmon DR, Trampuz A, Steckelberg JM, Patel R (2005) High rate of aminoglycoside resistance among staphylococci causing prosthetic joint infection. Clin Orthop Relat Res 439: 43-47.

Ravi S, Zhu M, Luey C, Young SW (2016) Antibiotic resistance in early periprosthetic joint infection. ANZ J Surg 86: 1014-1018.

Tande AJ and Patel R (2014) Prosthetic joint infection. Clin Microbiol Rev 27: 302-345.

Zimmerli W, Waldvogel FA, Vaudaux P, Nydegger UE (1982) Pathogenesis of foreign body infection: description and characteristics of an animal model. J Infect Dis 146: 487-497.

Editor's note: The Guest Editor responsible for this paper was Henny Van der Mei. 